\title{
Centrality of striatal cholinergic transmission in basal ganglia function
}

\section{Paola Bonsi' , Dario Cuomo², Giuseppina Martella ${ }^{2}$, Graziella Madeo ${ }^{2}$,Tommaso Schirinzi ${ }^{2}$, Francesca Puglisi', Giulia Ponterio ${ }^{1}$ and Antonio Pisani ${ }^{1,2 *}$}

Laboratory of Neurophysiology and Plasticity, Fondazione Santa Lucia IRCCS, Rome, Italy

2 Department of Neuroscience, University Tor Vergata, Rome, Italy

Edited by:

Jose L. Lanciego, University of

Navarra, Spain

\section{Reviewed by:}

James M. Tepper, Rutgers, The State

University of New Jersey, USA

Enrico Bracci, University of

Manchester, UK

*Correspondence:

Antonio Pisani, Department of

Neuroscience, University Tor Vergata,

Via Montpellier 1, 00133 Rome, Italy.

e-mail: pisani@uniroma2.it
Work over the past two decades revealed a previously unexpected role for striatal cholinergic interneurons in the context of basal ganglia function. The recognition that these interneurons are essential in synaptic plasticity and motor learning represents a significant step ahead in deciphering how the striatum processes cortical inputs, and why pathological circumstances cause motor dysfunction. Loss of the reciprocal modulation between dopaminergic inputs and the intrinsic cholinergic innervation within the striatum appears to be the trigger for pathophysiological changes occurring in basal ganglia disorders. Accordingly, there is now compelling evidence showing profound changes in cholinergic markers in these disorders, in particular Parkinson's disease and dystonia. Based on converging experimental and clinical evidence, we provide an overview of the role of striatal cholinergic transmission in physiological and pathological conditions, in the context of the pathogenesis of movement disorders.

Keywords: acetylcholine, striatum, interneuron, Parkinson's disease, dystonia, movement disorders

\section{INTRODUCTION}

The basal ganglia include different interconnected subcortical nuclei that are involved in serving critical motivation, motor planning, and procedural learning function (Graybiel et al., 1994; Yin and Knowlton, 2006; Nicola, 2007; Kreitzer and Malenka, 2008). The striatum represents the main input nucleus of the basal ganglia. It receives excitatory afferents from the cortex and thalamus, and is densely innervated by midbrain dopamine neurons (Bolam et al., 2000; Kreitzer and Malenka, 2008).

The large majority of striatal neurons are GABAergic. Most of these GABAergic neurons are represented by medium spiny projection neurons (MSNs; Izzo et al., 1987). At least three types of GABAergic interneurons have been identified, according to their electrophysiological and neurochemical properties. GABAergic interneurons may colocalize with the calcium-binding proteins parvalbumin or calretinin, or neuropeptide $\mathrm{Y}$, somatostatin, and NADPH diaphorase (Kawaguchi, 1993; Tepper and Bolam, 2004). Accordingly, they have been classified, respectively, as fast-spiking (FS) neurons, persistent and low-threshold spike (PLTS) neurons, or low-threshold spike (LTS) neurons (Kawaguchi et al., 1989; Tepper and Bolam, 2004). A recent study has characterized an additional group of GABAergic interneurons, expressing tyrosine hydroxylase $\left(\mathrm{TH}^{+}\right)$, which have been electrophysiologically classified into four distinct types (Tepper et al., 2010). Indeed, the existence of $\mathrm{TH}^{+}$ neurons in the striatum of rodents and primates had been reported since the late 1980s (for review, see Ibáñez-Sandoval et al., 2010).

In addition to the numerically prevailing population of GABAergic neurons, the striatum also contains a small percentage of interneurons which provide this area with one of the highest acetylcholine (ACh) levels in the brain (Graybiel, 1990; Mesulam et al., 1992; Contant et al., 1996). These are the large aspiny cholinergic interneurons (ChIs) characterized by dense local axonal arborizations, and by tonic firing activity (Bolam et al., 1984; Wilson et al., 1990; Kawaguchi, 1993; Aosaki et al., 1995; Bennett and Wilson, 1998; Bennett et al., 2000; Zhou et al., 2002).

It has long been known that striatal ChIs play a central role in the basal ganglia circuitry both in the control of voluntary movements and in the pathophysiology of movement disorders, such as Parkinson's disease (PD), and dystonia (Pisani et al., 2003a, 2007; Aosaki et al., 2010). Indeed, anticholinergic drugs have long been a first choice therapy for PD and dystonia (Duvoisin, 1967; Jankovic, 2006). Here, in light of the most recent findings, we will review the role of ChIs in striatal function and in the pathogenesis of basal ganglia disorders.

\section{MORPHOLOGICAL AND ELECTROPHYSIOLOGICAL PROPERTIES OF CHOLINERGIC INTERNEURONS}

Large aspiny ChIs represent less than $2 \%$ of the entire striatal neuronal population. Their neurochemical identification is due to the expression of ChAT, the biosynthetic enzyme for ACh. Morphologically (Figures 1A,B), they are characterized by a large polygonal soma ( fields (Bolam et al., 1984; Smith and Bolam, 1990; Wilson et al., 1990), and a preferential distribution in the matrix area flanking the patches border (van Vulpen and van der Kooy, 1998). These features suggest that ChIs may integrate synaptic inputs over relatively large regions, and act as an associative interneuron in the striatum (Kawaguchi et al., 1995; Miura et al., 2007).

In vitro electrophysiological recordings have described the peculiar membrane properties of ChIs, that distinguish these neurons from all other striatal neuronal subtypes (Figures 1C-E). These include a relatively depolarized resting membrane potential, longlasting action potential, high input resistance, prominent afterhyperpolarization (AHP) current, and hyperpolarization-activated 


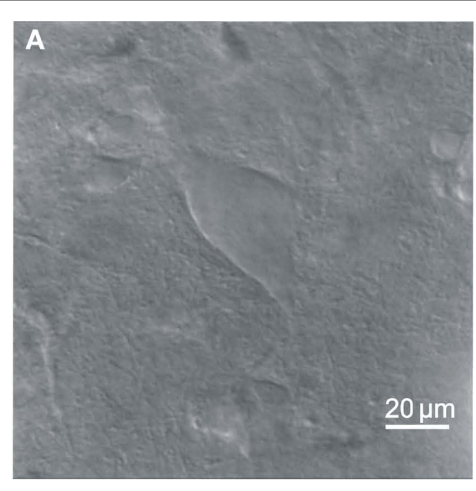

C
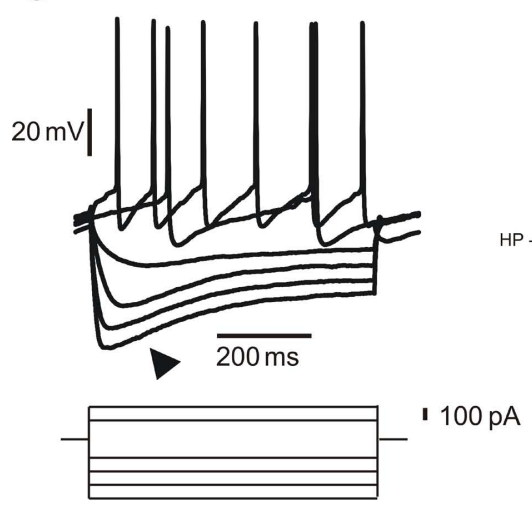

E

\begin{tabular}{|c|c|c|c|}
\hline $\begin{array}{c}\text { Resting membrane } \\
\text { potential }(\mathrm{mV})\end{array}$ & $\begin{array}{c}\text { Action potential } \\
\text { amplitude }(\mathrm{mV})\end{array}$ & AHP duration $(\mathrm{ms})$ & Input resistance $(\mathrm{M} \Omega)$ \\
\hline$-62 \pm 2.7$ & $64.5 \pm 3.9$ & $340 \pm 50$ & $143 \pm 41$ \\
\hline
\end{tabular}

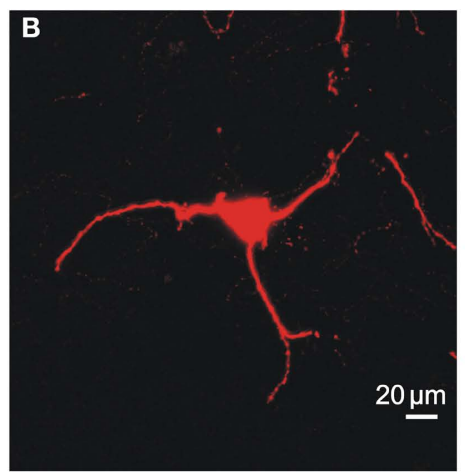

D

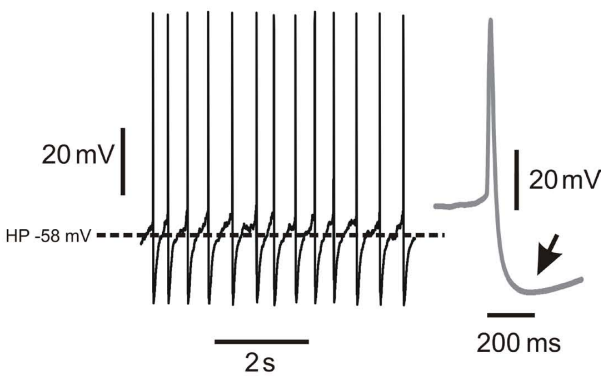

FIGURE 1 | Morphological and electrophysiological properties of striatal cholinergic interneurons. (A) Infrared differential interference contrast image of a cholinergic interneuron in a striatal slice showing the peculiar polygonal shape and large somatic size of this neuronal subtype. (B) Confocal microscope image of a biocytin-loaded cholinergic interneuron. The cell was loaded with $2 \%$ biocytin by means of the recording electrode during an electrophysiological experiment. Note the absence of spines along the 


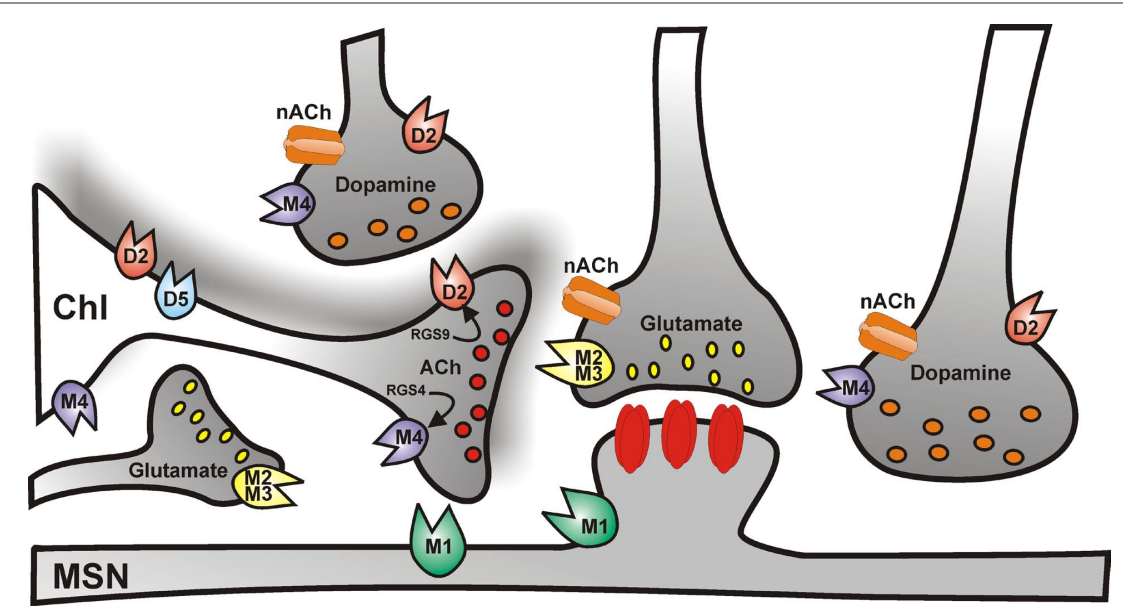

FIGURE 2 | Cholinergic control of striatal medium spiny neuron activity. Simplified cartoon of the striatal circuitry reporting the distribution of muscarinic and nicotinic receptors. Cholinergic receptors regulate the activity of medium spiny neurons both at the postsynaptic level, and presynaptically, by modulating glutamate, dopamine, and acetylcholine neurotransmission.

The predominant effect of dopamine on ChIs is mediated by activation of D2-like $\mathrm{D}_{2}$ receptors (Figure 2), which inhibit striatal ACh efflux (DeBoer et al., 1996), by reducing both autonomous action potential firing and synaptic inputs to ChIs. The former effect is achieved by enhancing the slow inactivation of voltagedependent $\mathrm{Na}^{+}$channels (Maurice et al., 2004) and by modulating $I_{h}$ current (Deng et al., 2007). The reduction of synaptic inputs is achieved through inhibition of $\mathrm{HVA} \mathrm{Ca}^{2+}$ channel (Yan and Surmeier, 1996; Pisani et al., 2000).

In addition, striatal ChIs express D1-like $\mathrm{D}_{5}$ subtype receptors (Figure 2; Bergson et al., 1995; Yan and Surmeier, 1997), which are mainly somatodendritic and depolarize the cell by promoting the non-selective opening of cation channels and the closure of $\mathrm{K}^{+}$channels, thus, in turn, enhancing ACh release (Damsma et al., 1990; Imperato et al., 1993; DeBoer and Abercrombie, 1996; Aosaki et al., 1998; Pisani et al., 2000).

An additional level of control of striatal $\mathrm{ACh}$ release is represented by M2/M4 muscarinic autoreceptors (Figure 2). Autoreceptor activation reduces $\mathrm{ACh}$ release by closing $\mathrm{Ca}_{\mathrm{v}} 2 \mathrm{Ca}^{2+}$ channels which mediate exocytosis, and by increasing opening of Kir3 potassium channels, which hyperpolarize terminals and further reduce $\mathrm{Ca}^{2+}$ channel opening (Yan and Surmeier, 1996; Calabresi et al., 1998b).

Furthermore, ChIs receive extrinsic excitatory serotonergic (Lavoie et al., 1989; Bonsi et al., 2007) and noradrenergic afferents (Pazos et al., 1985; Pisani et al., 2003b), and an intrinsic inhibitory GABAergic innervation from both MSNs and FS interneurons (Bolam et al., 1986; Martone et al., 1992; Aosaki et al., 2010).

Postsynaptic potentials evoked by electrical stimulation of fibers innervating ChIs are mediated by activation of ionotropic NMDA, AMPA, and $\mathrm{GABA}_{\mathrm{A}}$ receptors. Upon complete inhibition of both the glutamatergic and GABAergic synaptic components, a slow inhibitory synaptic potential is unmasked, which is mediated by a $\mathrm{K}^{+}$conductance activated by $\mathrm{M} 2$-like receptors (Calabresi et al., 1998b).
The activity of striatal ChIs is therefore highly regulated, through a complex interaction between intrinsic properties and the neuromodulatory control exerted by several transmitters.

\section{ORIGIN OF THE PAUSE RESPONSE IN ChI TONIC FIRING ACTIVITY}

Striatal ChIs exhibit a variety of spontaneous firing patterns also during in vivo recordings (Wilson et al., 1990; Reynolds et al., 2004). Indeed, these neurons correspond to the tonically active neurons (TANs) recorded in vivo from the primate striatum, which respond with a pause in their ongoing firing activity to reward-related stimuli (Apicella et al., 1991, 1998; Aosaki et al., 1994; ). Several mechanisms are likely to contribute to this pause response, through the modulation of both intrinsic and synaptic properties of ChIs. It has been suggested that these pauses in firing may be due to AHP currents intrinsically generated via $\mathrm{I}_{\mathrm{h}}$ transient deactivation following cortical excitatory synaptic inputs (Reynolds et al., 2004; Oswald et al., 2009). Of interest, $I_{h}$ is regulated by dopamine (Deng et al., 2007). In fact, it is known that synaptic inputs arising both from the dopaminergic nigrostriatal system and from thalamic nuclei involved in sensorimotor integration modulate the responsiveness of these neurons to reward-related stimuli (Aosaki et al., 1994; Matsumoto et al., 2001). High-frequency stimulation (HFS) of the substantia nigra during in vivo recordings increases the AHP (Reynolds et al., 2004). Similarly, in neurons exhibiting regular firing in vitro exogenous application of dopamine causes a prolongation of a depolarization-induced pause and an increase in the duration of sAHP (Deng et al., 2007). Recent in vitro experimental evidence shed further light on the origin of the pause response in striatal ChIs (Ding et al., 2010). This report showed that high-frequency thalamic stimulation elicits an initial burst followed by a pause in the firing activity of ChIs. Both $\mathrm{D}_{2}$ dopamine and nicotinic $\mathrm{ACh}(\mathrm{nACh})$ receptors were shown to be involved in this response. These data suggest that the biphasic response to thalamic stimulation might be driven by the initial excitation of ChIs, which induces ACh release and activation of presynaptic $\mathrm{nACh}$ receptors located on dopaminergic 
terminals (Figure 2); hence the stimulation of dopamine release and $\mathrm{D}_{2}$ receptor activation, which prolongs the AHP by inhibiting $\mathrm{I}_{\mathrm{h}}$ and $\mathrm{Na}^{+}$channel currents (Aosaki et al., 2010).

Striatal ChIs have been shown, both in vivo and in vitro, to undergo long-term plastic changes of synaptic efficacy, which might lastingly influence the pattern of firing activity (Suzuki et al., 2001b; Bonsi et al., 2004; Reynolds et al., 2004; Fino et al., 2008). In slice preparations HFS of glutamatergic afferent fibers induces a longterm potentiation (LTP) of both the AMPA-mediated excitatory and GABAergic inhibitory postsynaptic potentials, which is dependent on $\mathrm{D}_{5}$ receptor activation, and on a critical level of intracellular $\mathrm{Ca}^{2+}$ rise through $\mathrm{Ca}_{\mathrm{v}} 1$ channels (Suzuki et al., 2001b; Bonsi et al., 2004). Interestingly, intracellular recordings of ChIs from striatal slices of rats that have learned a rewarded, externally cued sensorimotor task show an increase in spontaneous $\mathrm{GABA}_{\mathrm{A}}$-mediated synaptic activity with respect to untrained animals (Bonsi et al., 2003), further suggesting a role for GABAergic transmission in the generation of the pause response. More recently, spike-timing-dependent plasticity (STDP) protocols were shown to induce bidirectional long-term plasticity in ChIs (Fino et al., 2008). STDP-LTP was mainly presynaptic and involved NMDA-receptor activation, while long-term depression (STDP-LTD) had a postsynaptic origin and involved metabotropic glutamate receptors.

Thus, it is plausible that long-term changes of both glutamatergic and GABAergic synaptic potential amplitude are also involved in the generation of the firing activity pattern (Aosaki et al., 2010).

The pattern of spiking and pauses of ChIs is able to filter the striatal output, by directly and indirectly influencing MSN activity (Phelps et al., 1985; Izzo and Bolam, 1988; Chang and Kita, 1992; Wang et al., 2006; Pakhotin and Bracci, 2007; Bonsi et al., 2008). There is experimental evidence indicating that the pauses in ChIs activity might powerfully enhance the salience of dopamine signaling (Threlfell et al., 2010) and transform the reward signal arising from dopaminergic neurons into a gating signal for LTD induction at MSNs (Wang et al., 2006). Further, the thalamic-induced burstpause response of ChIs might provide a neural substrate for attentional shift and cessation of ongoing motor activity (Ding et al., 2010). Indeed, the patterned activity of ChIs has been suggested to differentially gate the cortical drive to striatopallidal and striatonigral MSNs. Upon thalamic stimulation, the initial burst response of ChIs triggers the transient suppression of cortical inputs to MSNs, through presynaptic muscarinic M2-class receptor activation, but also initiate a slower, muscarinic M1 receptor-dependent postsynaptic facilitation of striatopallidal MSNs. This facilitation extends during the pause response, when the cortical drive resumes, thus creating a late temporal window when the corticostriatal input can selectively drive activity in the striatopallidal network thought to control action suppression (Ding et al., 2010).

\section{MUSCARINIC AND NICOTINIC MODULATION OF MSN ACTIVITY}

A very dense cholinergic innervation of the striatum arises from intrinsic ChIs. By tonically firing action potentials at about $5 \mathrm{~Hz}$, these interneurons provide an ongoing ACh signal, that is rapidly terminated by acetylcholinesterase (AChE). ACh may act both at synaptic sites, predominantly onto distal dendrites and spine necks (Bolam et al., 1984; Phelps et al., 1985), and via volume transmission (Descarries et al., 1997; Koos and Tepper, 2002).
In the striatum, different subtypes of $\mathrm{nACh}$ receptors have been identified, containing a combination of the $\alpha 4, \alpha 6, \alpha 7$, and $\beta 2, \beta 3$ subunits (Wada et al., 1989; Seguela et al., 1993; for review, see Quik et al., 2007). In addition, both M1-like and M2-like muscarinic ACh ( $\mathrm{mACh})$ receptors, predominantly the M1 and M4 subtypes, are expressed at high density (Figure 2).

In MSNs, M1 receptor activation enhances NMDA-receptormediated currents, promoting cell depolarization and corticostriatal LTP (Calabresi et al., 2000), and increases the synchrony in the NMDA-induced network dynamics, via enhancement of persistent $\mathrm{Na}^{+}$current (Carrillo-Reid et al., 2009). In addition, M1 receptors modulate HVA Ca ${ }^{2+}$ currents (Howe and Surmeier, 1995; Galarraga et al., 1999; Olson et al., 2005; Perez-Rosello et al., 2005; Perez-Burgos et al., 2008, 2010). Recently, M1 receptor activation has been suggested to have cell-specific effects on striatopallidal vs. striatonigral MSNs, due to specific characteristics of the downstream effectors (Chen et al., 2006; Shen et al., 2007; Day et al., 2008).

In addition to direct postsynaptic effects on MSNs, presynaptic ACh receptors regulate both glutamate and GABA release from striatal afferents. While $\mathrm{mACh}$ receptors inhibit neurotransmitter release, presynaptic nACh receptors exert the opposite effect (Calabresi et al., 1998a; Koos and Tepper, 2002; Zhou et al., 2002; Grilli et al., 2009; McClure-Begley et al., 2009).

The autonomous activity of ChIs ensures a sufficient level of endogenous ACh to tonically activate $\mathrm{mACh}$ and $\mathrm{nACh}$ receptors, thereby constantly influencing striatal activity. Through mACh receptor activation, $\mathrm{ACh}$ provides a presynaptic inhibitory tone on the excitatory glutamatergic drive onto MSNs (Pakhotin and Bracci, 2007). Indeed, a single spike in a ChI is able to induce a significant $\mathrm{mACh}$ receptor-mediated depression of glutamatergic synaptic currents in a MSN. However, a mechanism to limit this powerful inhibitory control of ChIs over the glutamatergic input to MSNs has been recently proposed to reside in the nicotinic excitation of striatal GABAergic interneurons (Sullivan et al., 2008).

Overall, nACh and $\mathrm{mACh}$ receptors would act to translate the pattern of the ongoing cholinergic activity into a strong influence over striatal output (Koos and Tepper, 2002): nACh receptor activation would rapidly affect the activity of MSNs, while the muscarinic impact might become more evident on a slower time scale, and in particular when additional extrasynaptic volume transmission extends the duration of the ACh signal, such as during periods of more intense cholinergic activity (Singer et al., 2002).

\section{STRIATAL ACETYLCHOLINE AND SYNAPTIC PLASTICITY}

Enduring changes in synaptic efficacy at corticostriatal synapses are viewed as the cellular basis underlying motor learning and associative memory processes. HFS of corticostriatal afferents may induce either LTD or LTP at MSN synapses, depending on a variety of cellspecific mechanisms (Calabresi et al., 1992; Lovinger et al., 1993; Surmeier et al., 2009). Induction of LTD and LTP requires an intact nigrostriatal projection, and depends upon both dopamine and ionotropic glutamate receptor subtypes involved (Lovinger, 2010). Complex biochemical processes follow the activation of glutamatergic and dopaminergic receptors and their mutual interplay (Calabresi et al., 1994; Gerdeman et al., 2002). 
M1 mACh receptors are abundantly expressed on dendrites and spines of MSNs (Figure 2), and are therefore likely to exert a relevant influence on synaptic plasticity (Hersch et al., 1994; Yan et al., 2001). In fact, activation of postsynaptic M1 muscarinic receptors increases MSN excitability, by reducing dendritic $\mathrm{K}^{+}$currents (Galarraga et al., 1999; Shen et al., 2005). As a consequence, M1 receptor activation promotes MSN depolarization and plays a permissive role in corticostriatal LTP (Calabresi et al., 1999). Accordingly, the M1 receptor antagonist pirenzepine prevents LTP, whilst methoctramine, an M2-like receptor blocker, enhances the magnitude of this form of synaptic plasticity (Calabresi et al., 2000). In addition, $\mathrm{M} 1$ receptor activation reduces the opening of $\mathrm{Ca}_{\mathrm{v}} 1$ channels, in response to depolarization, that is necessary for LTD induction (Calabresi et al., 1994; Choi and Lovinger, 1997; Kreitzer and Malenka, 2005). Indeed, LTD induction requires $\mathrm{D}_{2}$ receptor activation in order to pause ChI firing activity and reduce M1 receptor tone (Wang et al., 2006).

In summary, manipulation of ACh tone is expected to affect the direction of corticostriatal synaptic plasticity. In fact, loss of autoreceptor function in M2/M4 receptor knockout mice increases striatal ACh tone and impairs selectively LTD induction at MSN synapses. Accordingly, in these mice LTD can be restored by reducing ACh levels with hemicholinium-3, which depletes endogenous ACh (Bonsi et al., 2008).

\section{CHOLINERGIC SIGNALING IN DISEASE STATES PARKINSON'S DISEASE}

In the early 1960s anticholinergic drugs were introduced in the pharmacological treatment of PD, according to the evidence of an imbalance between dopaminergic and cholinergic transmission within the striatum (Barbeau, 1962; Duvoisin, 1967; Hornykiewicz and Kish, 1987).

Although the increased striatal ACh level has long been attributed to the removal of tonic inhibitory control by $\mathrm{D}_{2}$ receptors on ChIs (Maurice et al., 2004), recent experimental work has investigated in more detail ChI function in acute dopamine depletion models of PD (Fino et al., 2007; Salin et al., 2009). As expected, in dopamine-depleted animals ChIs displayed an increased excitability in vitro (Fino et al., 2007), and became highly synchronized in firing rhythmic bursts in vivo (Raz et al., 1996, 2001). This altered pattern of activity might result in periodic outbreaks of ACh release into the striatum which might not be readily hydrolyzed by AChE. Such alterations in ACh input are likely to underlie the loss of synaptic plasticity (Pisani et al., 2005) and to contribute to the pruning of spines (Shen et al., 2007) reported in MSNs from dopaminedepleted animals, contributing to imbalanced striatal outflow in the parkinsonian state.

Interestingly, recent experimental evidence revealed a novel mechanism by which $\mathrm{mACh}$ receptor signaling would disrupt striatal activity (Ding et al., 2006). "Regulators of G protein signaling" (RGS) proteins are GTPase accelerating proteins (GAPs), which terminate G protein coupling between receptors and effectors. Alterations in dopamine content have been shown to rapidly modify the expression of several RGS proteins. These authors report that dopamine depletion does not alter $\mathrm{D}_{2}$ dopamine receptor signaling in ChIs, but leads to a decreased mACh M4 receptor coupling to $\mathrm{Ca}^{2+}$ channels, thereby modifying
ChIs excitability. Moreover, they show that this impaired coupling is caused by the selective upregulation of RGS4 expression (Ding et al., 2006).

A very recent paper by Ding et al. (2011) has suggested unexpected roles for ChIs also in the adverse motor effects, dyskinesias, induced by prolonged treatment of PD patients with the dopamine replacing agent 3,4-L-dihydroxphenylalanine methyl ester (L-DOPA). These authors have shown in PD rodent models that repeated L-DOPA exposure causes activation of extracellular signal-regulated kinase $1 / 2$ (ERK) and, in turn, an increased basal firing rate and dopamine-dependent excitation in striatal ChIs. These specific responses of ChIs to chronic L-DOPA treatment correlated with the expression of dyskinesia. Accordingly, muscarinic receptor antagonism reduced L-DOPA-induced dyskinesia.

\section{DYSTONIA}

As in $\mathrm{PD}$, anticholinergic drugs targeting $\mathrm{mACh}$ receptors are also effective in the treatment of another movement disorder, dystonia. DYT1 dystonia is a severe form of inherited dystonia, characterized by involuntary twisting movements and abnormal postures. Although the pathogenesis of this disabling disorder remains to be fully elucidated, an altered coupling of dopaminergic and cholinergic signaling has been recently demonstrated in the striatum of mice over-expressing the human protein torsinA with the mutation responsible for DYT1 dystonia (Pisani et al., 2006). In these mice, $\mathrm{D}_{2}$ receptor activation induces an excitatory, rather than inhibitory, effect in ChIs. This paradoxical effect was associated to an increase in the functional representation of $\mathrm{Ca}_{\mathrm{v}} 2 \mathrm{Ca}^{2+}$ channels, that regulate $\mathrm{Ca}^{2+}$ entry and the physiological pacemaking activity of these interneurons, likely enhancing ACh release. Indeed, the activity of endogenous AChE was increased in the striatum of DYT1 mice, suggesting a compensatory mechanism to reduce an increased cholinergic tone. In accordance to the proposed role of ACh levels in determining the direction of corticostriatal synaptic plasticity (Bonsi et al., 2008), the elevation in cholinergic tone in DYT1 mice was correlated to the loss of LTD and synaptic depotentiation, and the enhancement of LTP (Martella et al., 2009). This notion was supported by the observation that these alterations were normalized by lowering ACh tone with hemicholinium-3, a depletor of endogenous ACh. Moreover, the clinical drug trihexyphenidyl as well as pirenzepine, both $\mathrm{mACh} \mathrm{M} 1$ receptor antagonists, were effective in restoring normal synaptic plasticity. These observations might explain the efficacy of anticholinergic drugs in the treatment of dystonia.

\section{OTHER MOVEMENT DISORDERS}

Functional imaging and post-mortem studies have revealed a significant loss of striatal cholinergic markers in different basal ganglia disorders (Suzuki et al., 2002; Warren et al., 2005; Smith et al., 2006; Kataoka et al., 2010). Huntington's disease (HD) is an autosomal dominant neurodegenerative disease, caused by a mutation in the gene encoding Huntingtin, characterized by involuntary choreiform movements, behavioral and cognitive impairment. Though striatal ChIs have been reported to be spared during striatal degeneration in HD (Graveland et al., 1985), recent studies suggest that they might be functionally altered. Indeed, the levels of both the vesicular ACh transporter (VAChT) and choline acetyltransferase 
(ChAT) are markedly decreased in the striatum of HD transgenic mice, as well as in post-mortem striatal tissue from HD patients (Spokes, 1980; Suzuki et al., 2001a; Vetter et al., 2003; Smith et al., 2006). Moreover, in two experimental models of HD, 3-nitropropionic acid-treated rats and R6/2 transgenic mice, striatal ChIs did not express LTP (Picconi et al., 2006). Progressive supranuclear palsy (PSP) is a progressive neurodegenerative disease characterized by accumulation of tau protein and akinetic-rigid features, falls, supranuclear gaze palsy, and subcortical dementia. In this disorder, cholinergic dysfunction is indicated by reduced levels of ChAT and VAChT in post-mortem samples, as well as by loss of striatal ChIs (Suzuki et al., 2002; Warren et al., 2005).

Chronic clinical use of dopaminergic drugs is often associated with the development of different types of motor complications, such as dystonia, parkinsonism, hyperkinesia, and stereotyped behavior. These reactions to dopaminergic agents points to an imbalance between striatal ACh and dopamine levels. Accordingly, the treatment of choice for these complications is represented by cholinergic drugs (Sethi and Morgan, 2007; Cubo et al., 2008). In the case of motor stereotypy, as well as of Tourette's syndrome (TS), a childhood-onset neuropsychiatric disease characterized by motor and vocal tics (Graybiel and Canales, 2001) and by a reduced striatal volume (Peterson et al., 2003), a cholinesterase inhibitor has been reported to be effective in the clinical practice (Cubo et al., 2008). Notably, a recent stereological analysis of post-mortem brains showed a significant reduction in the number of ChIs in the sensorimotor regions of the striatum in TS patients (Kataoka et al., 2010). Accordingly, a key role of striatal ChIs has been demonstrated in the arrest of cocaine-induced motor stereotypy in a rat model, where pharmacological treatments restoring ACh release rapidly blocked movement dysfunction (Aliane et al., 2010). Interestingly, this study showed that, while the striatal dopamine/ACh balance is effective during the period of strong motor stereotypy (dopamine increases and ACh decreases), it becomes dissociated during the

\section{REFERENCES}

Aliane, V., Perez, S., Bohren, Y., Deniau, J. M., and Kemel, M. L. (2010). Key role of striatal cholinergic interneurons in processes leading to arrest of motor stereotypies. Brain. doi: 10.1093/brain/ awq285. [Epub ahead of print].

Aosaki, T., Kimura, M., and Graybiel, A. M. (1995). Temporal and spatial characteristics of tonically active neurons of the primate's striatum. J. Neurophysiol. 73, 1234-1252.

Aosaki, T., Kiuchi, K., and Kawaguchi, Y. (1998). Dopamine D1-like receptor activation excites rat striatal large aspiny neurons in vitro. J. Neurosci. 18, 5180-5190.

Aosaki, T., Miura, M., Suzuki, T., Nishimura, K., and Masuda, M. (2010). Acetylcholine-dopamine balance hypothesis in the striatum: an update. Geriatr. Gerontol. Int. 10(Suppl. 1), S148-S157.

Aosaki, T., Tsubokawa, H., Ishida, A., Watanabe, K., Graybiel, A. M., and Kimura, M. (1994). Responses of

phase of motor recovery. Indeed, in this period dopamine level still remains high, while ACh returns to its basal level mirroring the decreasing intensity of stereotypy, suggesting an important role of cholinergic transmission in the arrest of motor stereotypy. In accordance with this hypothesis, pharmacological blockade of muscarinic receptors as well as lesion of ChIs significantly prolonged motor stereotypy.

Although simplistic, the striatal ACh/dopamine balance view finds support in clinical pharmacological evidence. To date, two major categories of drugs are successfully utilized in the management of most movement disorders: drugs interfering with either dopaminergic or cholinergic function, suggesting that the interplay between these transmitters is relevant to the maintenance of a correct motor control. In our view, a perspective based upon cholinergic dysfunction may prove useful to orientate clinical pharmacological reasoning.

\section{CONCLUDING REMARKS}

Clues from neurobiology, functional imaging studies and postmortem data converge to suggest that both pathogenic features and clinical phenomenology of distinct movement disorders are closely related to dysfunction of striatal cholinergic signaling.

To date, therapeutic intervention to most of these disorders is unsatisfactory. In those conditions where an increased cholinergic activity is documented, targeting muscarinic receptors with more selective drugs is warranted. Indeed, both in PD and dystonia, enhancing M2/M4-mediated autoreceptor function, either by developing selective agonists, or by modulating $\mathrm{Ca}_{\mathrm{v}} 2 \mathrm{Ca}^{2+}$ channels appears a promising strategy.

The development of new animal models, including transgenic mice, as well as muscarinic and nicotinic receptor knockout mice, is moving research to a level in which the physiology of the receptor subtypes could be addressed in vivo, offering new perspectives for their pharmacological manipulation.

timing in neostriatal cholinergic interneurons. J. Neurosci. 18, 8539-8549.

Bennett, B. D., and Wilson, C. J. (1999). Spontaneous activity of neostriatal cholinergic interneurons in vitro. $J$. Neurosci. 19, 5586-5596.

Bergson, C., Mrzljak, L., Smiley, J. F., Pappy, M., Levenson, R., and Goldman-Rakic, P. S. (1995). Regional, cellular, and subcellular variations in the distribution of D1 and D5 dopamine receptors in primate brain. J. Neurosci. 15, 7821-7836.

Bolam, J. P., Hanley, J. J., Booth, P. A., and Bevan, M. D. (2000). Synaptic organisation of the basal ganglia. $J$. Anat. 196(Pt 4), 527-542.

Bolam, J. P., Ingham, C. A., Izzo, P. N., Levey, A. I., Rye, D. B., Smith, A. D., and Wainer, B. H. (1986). Substance $\mathrm{P}$-containing terminals in synaptic contact with cholinergic neurons in the neostriatum and basal forebrain: a double immunocytochemical study in the rat. Brain Res. 397, 279-289.
Bolam, J. P., Wainer, B. H., and Smith, A. D. (1984). Characterization of cholinergic neurons in the rat neostriatum. A combination of choline acetyltransferase immunocytochemistry, Golgi-impregnation and electron microscopy. Neuroscience 12, 711-718.

Bonsi, P., Cuomo, D., Ding, J., Sciamanna, G., Ulrich, S., Tscherter, A., Bernardi, G., Surmeier, D. J., and Pisani, A. (2007). Endogenous serotonin excites striatal cholinergic interneurons via the activation of 5-HT 2C, 5-HT6, and 5-HT7 serotonin receptors: implications for extrapyramidal side effects of serotonin reuptake inhibitors. Neuropsychopharmacology 32, 1840-1854.

Bonsi, P., De Persis, C., Calabresi, P., Bernardi, G., and Pisani, A. (2004). Coordinate high-frequency pattern of stimulation and calcium levels control the induction of LTP in striatal cholinergic interneurons. Learn. Mem. 11, 755-760. 
Bonsi, P., Florio, T., Capozzo, A., Pisani, A., Calabresi, P., Siracusano, A., and Scarnati, E. (2003). Behavioural learning-induced increase in spontaneous GABAA-dependent synaptic activity in rat striatal cholinergic interneurons. Eur. J. Neurosci. 17, 174-178.

Bonsi, P., Martella, G., Cuomo, D., Platania, P., Sciamanna, G., Bernardi, G., Wess, J., and Pisani, A. (2008). Loss of muscarinic autoreceptor function impairs long-term depression but not long-term potentiation in the striatum. J. Neurosci. 28, 6258-6263.

Calabresi, P., Centonze, D., Gubellini, P., and Bernardi, G. (1999). Activation of M1-like muscarinic receptors is required for the induction of corticostriatal LTP. Neuropharmacology $38,323-326$

Calabresi, P., Centonze, D., Gubellini, P., Pisani, A., and Bernardi, G. (1998a). Blockade of M2-like muscarinic receptors enhances long-term potentiation at corticostriatal synapses. Eur. J. Neurosci. 10, 3020-3023.

Calabresi, P., Centonze, D., Pisani, A., Sancesario, G., North, R. A., and Bernardi, G. (1998b). Muscarinic IPSPs in rat striatal cholinergic interneurones. J. Physiol. 510(Pt 2), 421-427.

Calabresi, P., Centonze, D., Gubellini, P., Pisani, A., and Bernardi, G. (2000). Acetylcholine-mediated modulation of striatal function. Trends Neurosci. 23, 120-126.

Calabresi, P., Maj, R., Pisani, A., Mercuri, N. B., and Bernardi, G. (1992). Longterm synaptic depression in the striatum: physiological and pharmacological characterization. J. Neurosci. $12,4224-4233$.

Calabresi, P., Pisani, A., Mercuri, N. B., and Bernardi, G. (1994). Post-receptor mechanisms underlying striatal long-term depression. J. Neurosci. 14, 4871-4881.

Carrillo-Reid, L., Tecuapetla, F., Vautrelle, N., Hernandez, A., Vergara, R., Galarraga, E., and Bargas, J. (2009). Muscarinic enhancement of persistent sodium current synchronizes striatal medium spiny neurons. $J$. Neurophysiol. 102, 682-690.

Chang, H. T., and Kita, H. (1992). Interneurons in the rat striatum: relationships between parvalbumin neurons and cholinergic neurons. Brain Res. 574, 307-311.

Chen, Y., Yu, F. H., Surmeier, D. J., Scheuer, T., and Catterall, W. A. (2006). Neuromodulation of $\mathrm{Na}+$ channel slow inactivation via cAMPdependent protein kinase and protein kinase C. Neuron 49, 409-420.

Choi, S., and Lovinger, D. M. (1997). Decreased probability of neurotransmitter release underlies striatal long-term depression and postnatal development of corticostriatal synapses. Proc. Natl. Acad. Sci. U.S.A. 94, 2665-2670.

Contant, C., Umbriaco, D., Garcia, S., Watkins, K. C., and Descarries, L. (1996). Ultrastructural characterization of the acetylcholine innervation in adult rat neostriatum. Neuroscience 71, 937-947.

Cubo, E., Fernandez Jaen, A., Moreno, C., Anaya, B., Gonzalez, M., and Kompoliti, K. (2008). Donepezil use in children and adolescents with tics and attention-deficit/hyperactivity disorder: an 18-week, single-center, dose-escalating, prospective, openlabel study. Clin. Ther. 30, 182-189.

Damsma, G., Tham, C. S., Robertson, G.S., and Fibiger, H. C. (1990). Dopamine D1 receptor stimulation increases striatal acetylcholine release in the rat. Eur. J. Pharmacol. 186, 335-338.

Day,M., Wokosin, D., Plotkin, J.L., Tian, X., and Surmeier, D. J. (2008). Differential excitability and modulation of striatal medium spiny neuron dendrites. J. Neurosci. 28, 11603-11614.

DeBoer, P., and Abercrombie, E. D. (1996). Physiological release of striatal acetylcholine in vivo: modulation by $\mathrm{D} 1$ and D2 dopamine receptor subtypes. J. Pharmacol. Exp. Ther. 277, 775-783.

DeBoer, P., Heeringa, M. J., and Abercrombie, E. D. (1996). Spontaneous release of acetylcholine in striatum is preferentially regulated by inhibitory dopamine $\mathrm{D} 2$ receptors. Eur. J. Pharmacol. 317, 257-262.

Deng, P., Zhang, Y., and Xu, Z. C. (2007). Involvement of $\mathrm{I}(\mathrm{h})$ in dopamine modulation of tonic firing in striatal cholinergic interneurons. J. Neurosci. 27, 3148-3156.

Descarries, L., Gisiger, V., and Steriade, M. (1997). Diffuse transmission by acetylcholine in the CNS. Prog. Neurobiol. 53, 603-625.

Dimova, R., Vuillet, J., Nieoullon, A., and Kerkerian-Le Goff, L. (1993). Ultrastructural features of the choline acetyltransferase-containing neurons and relationships with nigral dopaminergic and cortical afferent pathways in the rat striatum. Neuroscience 53, 1059-1071.

Ding, J., Guzman, J. N., Tkatch, T., Chen, S., Goldberg, J. A., Ebert, P. J., Levitt, P., Wilson, C. J., Hamm, H. E., and Surmeier, D. J. (2006). RGS4dependent attenuation of M4 autoreceptor function in striatal cholinergic interneurons following dopamine depletion. Nat. Neurosci. 9, 832-842.

Ding, J. B., Guzman, J. N., Peterson, J. D., Goldberg, J. A., and Surmeier, D. J. (2010). Thalamic gating of corticostriatal signaling by cholinergic interneurons. Neuron 67, 294-307.
Ding, Y., Won, L., Britt, J. P., Lim, S. A., McGehee, D. S., and Kang, U.J. (2011). Enhanced striatal cholinergic neuronal activity mediates L-DOPA-induced dyskinesia in parkinsonian mice. Proc. Natl. Acad. Sci. U.S.A. 108, 840-845.

Duvoisin, R. C. (1967). Cholinergicanticholinergic antagonism in parkinsonism. Arch. Neurol. 17, 124-136.

Fino, E., Deniau, J. M., and Venance, L. (2008). Cell-specific spike-timingdependent plasticity in GABAergic and cholinergic interneurons in corticostriatal rat brain slices. J. Physiol. $586,265-282$.

Fino, E., Glowinski, J., and Venance, L. (2007). Effects of acute dopamine depletion on the electrophysiological properties of striatal neurons. Neurosci. Res. 58, 305-316.

Galarraga, E., Hernandez-Lopez, S., Reyes, A., Miranda, I., Bermudez-Rattoni, F., Vilchis, C., and Bargas, J. (1999). Cholinergic modulation of neostriatal output: a functional antagonism between different types of muscarinic receptors. J. Neurosci. 19, 3629-3638.

Gerdeman, G. L., Ronesi, J., and Lovinger D. M. (2002). Postsynaptic endocannabinoid release is critical to longterm depression in the striatum. Nat. Neurosci. 5, 446-451.

Goldberg, J. A., Teagarden, M. A., Foehring, R. C., and Wilson, C. J. (2009). Nonequilibrium calcium dynamics regulate the autonomous firing pattern of rat striatal cholinergic interneurons. J. Neurosci. 29, 8396-8407.

Goldberg, J. A., and Wilson, C. J. (2005) Control of spontaneous firing patterns by the selective coupling of calcium currents to calcium-activated potassium currents in striatal cholinergic interneurons. J. Neurosci. 25, 10230-10238.

Graveland, G. A., Williams, R. S., and DiFiglia, M. (1985). Evidence for degenerative and regenerative changes in neostriatal spiny neurons in Huntington's disease. Science 227, 770-773.

Graybiel,A.M. (1990). Neurotransmitters and neuromodulators in the basal ganglia. Trends Neurosci. 13, 244-254.

Graybiel, A. M., Aosaki, T., Flaherty, A. W., and Kimura, M. (1994). The basal ganglia and adaptive motor control. Science 265, 1826-1831.

Graybiel, A. M., and Canales, J. J. (2001). The neurobiology of repetitive behaviors: clues to the neurobiology of Tourette syndrome. Adv. Neurol. 85, 123-131.

Grilli, M., Zappettini, S., Raiteri, L., and Marchi, M. (2009). Nicotinic and muscarinic cholinergic receptors coexist on GABAergic nerve endings in the mouse striatum and interact in modulating GABA release. Neuropharmacology 56, 610-614

Hersch, S. M., Gutekunst, C. A., Rees, H. D., Heilman, C. J., and Levey, A. I. (1994). Distribution of m1-m4 muscarinic receptor proteins in the rat striatum: light and electron microscopic immunocytochemistry using subtype-specific antibodies. $J$. Neurosci. 14,3351-3363.

Hornykiewicz, O., and Kish, S. J. (1987). Biochemical pathophysiology of Parkinson's disease. Adv. Neurol. 45, 19-34.

Howe, A. R., and Surmeier, D. J. (1995). Muscarinic receptors modulate N-, P-, and L-type $\mathrm{Ca} 2+$ currents in rat striatal neurons through parallel pathways. $J$. Neurosci. 15, 458-469.

Ibáñez-Sandoval, O., Tecuapetla, F., Unal, B., Shah, F., Koós, T., and Tepper, J. M. (2010). Electrophysiological and morphological characteristics and synaptic connectivity of tyrosine hydroxylase-expressing neurons in adult mouse striatum. J. Neurosci. 30, 6999-7016.

Imperato, A., Obinu, M. C., and Gessa, G. L. (1993). Effects of cocaine and amphetamine on acetylcholine release in the hippocampus and caudate nucleus. Eur. J. Pharmacol. 238, 377-381.

Izzo, P. N., and Bolam, J. P. (1988). Cholinergic synaptic input to different parts of spiny striatonigral neurons in the rat. J. Comp. Neurol. 269, 219-234.

Izzo, P. N., Graybiel, A. M., and Bolam, J. P. (1987). Characterization of substance P- and [Met] enkephalinimmunoreactive neurons in the caudate nucleus of cat and ferret by a single section Golgi procedure. Neuroscience 20, 577-587.

Jankovic, J. (2006). Treatment of dystonia. Lancet Neurol. 5, 864-872.

Kataoka, Y., Kalanithi, P. S., Grantz, H., Schwartz, M. L., Saper, C., Leckman, J. F., and Vaccarino, F. M. (2010). Decreased number of parvalbumin and cholinergic interneurons in the striatum of individuals with Tourette syndrome. J. Comp. Neurol. 518, 277-291.

Kawaguchi, Y. (1993). Physiological, morphological, and histochemical characterization of three classes of interneurons in rat neostriatum. $J$. Neurosci. 13, 4908-4923.

Kawaguchi, Y., Wilson, C. J., Augood, S. J., and Emson, P. C. (1995). Striatal interneurones: chemical, physiological and morphological characterization. Trends Neurosci. 18, 527-535.

Kawaguchi, Y., Wilson, C. J., and Emson, P. C. (1989). Intracellular recording of identified neostriatal patch and matrix spiny cells in a slice 
preparation preserving cortical inputs. J. Neurophysiol. 62, 1052-1068.

Koos, T., and Tepper, J. M. (2002). Dual cholinergic control of fast-spiking interneurons in the neostriatum. $J$. Neurosci. 22, 529-535.

Kreitzer, A.C., and Malenka, R. C. (2005). Dopamine modulation of state-dependent endocannabinoid release and long-term depression in the striatum. J. Neurosci. 25, 10537-10545.

Kreitzer,A.C., and Malenka, R. C. (2008). Striatal plasticity and basal ganglia circuit function. Neuron 60, 543-554.

Lapper, S. R., and Bolam, J. P. (1992). Input from the frontal cortex and the parafascicular nucleus to cholinergic interneurons in the dorsal striatum of the rat. Neuroscience 51, 533-545.

Lavoie, B., Smith, Y., and Parent, A. (1989). Dopaminergic innervation of the basal ganglia in the squirrel monkey as revealed by tyrosine hydroxylase immunohistochemistry. J. Comp. Neurol. 289, 36-52.

Lovinger, D. M. (2010). Neurotransmitter roles in synaptic modulation, plasticity and learning in the dorsal striatum. Neuropharmacology 58, 951-961.

Lovinger, D. M., Tyler, E. C., and Merritt, A. (1993). Short- and long-term synaptic depression in rat neostriatum. $J$. Neurophysiol. 70, 1937-1949.

Martella, G., Platania, P., Vita, D., Sciamanna, G., Cuomo, D., Tassone, A., Tscherter, A., Kitada, T., Bonsi, P., Shen, J., and Pisani, A. (2009). Enhanced sensitivity to group II mGlu receptor activation at corticostriatal synapses in mice lacking the familial parkinsonism-linked genes PINK1 or Parkin. Exp. Neurol. 215, 388-396.

Martone, M. E., Armstrong, D. M., Young, S. J., and Groves, P. M. (1992). Ultrastructural examination of enkephalin and substance $P$ input to cholinergic neurons within the rat neostriatum. Brain Res. 594, 253-262.

Matsumoto, N.,Minamimoto, T., Graybiel, A.M., and Kimura, M. (2001). Neurons in the thalamic CM-Pf complex supply striatal neurons with information about behaviorally significant sensory events. J. Neurophysiol. 85, 960-976.

Maurice, N., Mercer, J., Chan, C. S., Hernandez-Lopez, S., Held, J., Tkatch, T., and Surmeier, D. J. (2004). D2 dopamine receptor-mediated modulation of voltage-dependent $\mathrm{Na}+$ channels reduces autonomous activity in striatal cholinergic interneurons. J. Neurosci. 24, 10289-10301.

McClure-Begley, T.D., King, N.M., Collins, A.C.,Stitzel,J.A.,Wehner,J.M., and Butt, C. M. (2009).Acetylcholine-stimulated [3H]GABA release from mouse brain synaptosomes is modulated by alpha4beta2 and alpha4alpha5beta2 nicotinic receptor subtypes. Mol. Pharmacol. 75, 918-926.

Mesulam, M. M., Mash, D., Hersh, L., Bothwell, M., and Geula, C. (1992). Cholinergic innervation of the human striatum, globus pallidus, subthalamic nucleus, substantia nigra, and red nucleus. J. Comp. Neurol. 323, 252-268.

Miura, M., Saino-Saito, S., Masuda, M., Kobayashi, K., and Aosaki, T. (2007). Compartment-specific modulation of GABAergic synaptic transmission by mu-opioid receptor in the mouse striatum with green fluorescent protein-expressing dopamine islands. $J$. Neurosci. 27, 9721-9728.

Nicola, S. M. (2007). The nucleus accumbens as part of a basal ganglia action selection circuit. Psychopharmacology (Berl.) 191, 521-550.

Olson, L., Seiger, A., and Fuxe, K. (1972). Heterogeneity of striatal and limbic dopamine innervation: highly fluorescent islands in developing and adult rats. Brain Res. 44, 283-288.

Olson, P.A., Tkatch, T., Hernandez-Lopez, S., Ulrich, S., Ilijic, E., Mugnaini, E., Zhang, H., Bezprozvanny, I., and Surmeier, D. J. (2005). G-proteincoupled receptor modulation of striatal CaV1.3 L-type Ca2+ channels is dependent on a Shank-binding domain. J. Neurosci. 25, 1050-1062.

Oswald, M. J., Oorschot, D. E., Schulz, J. M., Lipski, J., and Reynolds, J. N. (2009). Ih current generates the afterhyperpolarisation following activation of subthreshold cortical synaptic inputs to striatal cholinergic interneurons. J. Physiol. 587, 5879-5897.

Pakhotin, P., and Bracci, E. (2007). Cholinergic interneurons control the excitatory input to the striatum. $J$. Neurosci. 27, 391-400.

Pazos, A., Probst, A., and Palacios, J. M. (1985). Beta-adrenoceptor subtypes in the human brain: autoradiographic localization. Brain Res. 358, 324-328.

Perez-Burgos, A., Perez-Rosello, T., Salgado, H., Flores-Barrera, E., Prieto, G. A., Figueroa, A., Galarraga, E., and Bargas, J. (2008). Muscarinic M(1) modulation of $\mathrm{N}$ and $\mathrm{L}$ types of calcium channels is mediated by protein kinase $\mathrm{C}$ in neostriatal neurons. Neuroscience 155, 1079-1097.

Perez-Burgos, A., Prieto, G. A., Galarraga, E., and Bargas, J. (2010). CaV2.1 channels are modulated by muscarinic M1 receptors through phosphoinositide hydrolysis in neostriatal neurons. Neuroscience 165, 293-299.

Perez-Rosello, T., Figueroa, A., Salgado, H., Vilchis, C., Tecuapetla, F., Guzman,
J. N., Galarraga, E., and Bargas, J. (2005). Cholinergic control of firing pattern and neurotransmission in rat neostriatal projection neurons: role of CaV2.1 and CaV2.2 Ca2+ channels. J. Neurophysiol. 93, 2507-2519.

Peterson, B. S., Thomas, P., Kane, M. J., Scahill, L., Zhang, H., Bronen, R., King, R. A., Leckman, J. F., and Staib, L. (2003). Basal Ganglia volumes in patients with Gilles de la Tourette syndrome. Arch. Gen. Psychiatry 60, 415-424.

Phelps, P. E., Houser, C. R., and Vaughn, J. E. (1985). Immunocytochemical localization of choline acetyltransferase within the rat neostriatum: a correlated light and electron microscopic study of cholinergic neurons and synapses. J. Comp. Neurol. 238, 286-307.

Picconi, B., Passino, E., Sgobio, C., Bonsi, P., Barone, I., Ghiglieri, V., Pisani, A., Bernardi, G., Ammassari-Teule, M. and Calabresi, P. (2006). Plastic and behavioral abnormalities in experimental Huntington's disease: a crucial role for cholinergic interneurons. Neurobiol. Dis. 22, 143-152.

Pisani, A., Bernardi, G., Ding, J., and Surmeier, D. J. (2007). Re-emergence of striatal cholinergic interneurons in movement disorders. Trends Neurosii. 30, 545-553.

Pisani, A., Bonsi, P., Centonze, D., Calabresi, P., and Bernardi, G. (2000). Activation of D2-like dopamine receptors reduces synaptic inputs to striatal cholinergic interneurons. J. Neurosci. 20, RC69.

Pisani, A., Bonsi, P., Centonze, D. Gubellini, P., Bernardi, G., and Calabresi, P. (2003a). Targeting striatal cholinergic interneurons in Parkinson's disease: focus on metabotropic glutamate receptors. Neuropharmacology 45, 45-56.

Pisani, A., Bonsi, P., Centonze, D., Martorana, A., Fusco, F., Sancesario, G., De Persis, C., Bernardi, G., and Calabresi, P. (2003b). Activation of betal-adrenoceptors excites striatal cholinergic interneurons through a cAMP-dependent, protein kinaseindependent pathway. J. Neurosci. 23, 5272-5282.

Pisani, A., Centonze, D., Bernardi, G., and Calabresi, P. (2005). Striatal synaptic plasticity: implications for motor learning and Parkinson's disease. Mov. Disord. 20, 395-402.

Pisani, A., Martella, G., Tscherter, A., Bonsi, P., Sharma, N., Bernardi, G., and Standaert, D. G. (2006). Altered responses to dopaminergic $\mathrm{D} 2$ receptor activation and $\mathrm{N}$-type calcium currents in striatal cholinergic interneurons in a mouse model of
DYT1 dystonia. Neurobiol. Dis. 24 318-325.

Quik, M., Bordia, T., and O'Leary, K. (2007). Nicotinic receptors as CNS targets for Parkinson's disease. Biochem. Pharmacol. 74, 1224-1234.

Raz, A., Feingold, A., Zelanskaya, V., Vaadia, E., and Bergman, H. (1996). Neuronal synchronization of tonically active neurons in the striatum of normal and parkinsonian primates. $J$. Neurophysiol. 76, 2083-2088.

Raz, A., Frechter-Mazar, V., Feingold, A., Abeles, M., Vaadia, E., and Bergman, H. (2001). Activity of pallidal and striatal tonically active neurons is correlated in mptp-treated monkeys but not in normal monkeys. J. Neurosci. 21, RC128.

Reynolds, J. N., Hyland, B. I., and Wickens, J. R. (2004). Modulation of an afterhyperpolarization by the substantia nigra induces pauses in the tonic firing of striatal cholinergic interneurons. $J$. Neurosci. 24, 9870-9877.

Salin, P., Lopez, I.P., Kachidian, P., BarrosoChinea, P., Rico, A. J., Gomez-Bautista, V., Coulon, P., Kerkerian-Le Goff, L. and Lanciego, J. L. (2009). Changes to interneuron-driven striatal microcircuits in a rat model of Parkinson's disease. Neurobiol. Dis. 34, 545-552.

Seguela, P., Wadiche, J., Dineley-Miller, K., Dani, J. A., and Patrick, J. W. (1993). Molecular cloning, functional properties, and distribution of rat brain alpha 7: a nicotinic cation channel highly permeable to calcium. J. Neurosci. 13, 596-604.

Sethi, K. D., and Morgan, J. C. (2007). "Drug-induced movement disorders," in Parkinson's Disease and Movement Disorders, 5th Edn, eds J. Jankovic and E. Tolosa (Philadelphia: Lippincott Williams and Wilkins), 394-408.

Shen, W., Hamilton, S. E., Nathanson, N. M., and Surmeier, D. J. (2005). Cholinergic suppression of KCNQ channel currents enhances excitability of striatal medium spiny neurons. J. Neurosci. 25, 7449-7458.

Shen, W., Tian, X., Day, M., Ulrich, S. Tkatch, T., Nathanson, N. M., and Surmeier, D. J. (2007). Cholinergic modulation of Kir2 channels selectively elevates dendritic excitability in striatopallidal neurons. Nat. Neurosci. 10, 1458-1466.

Sidibe, M., and Smith, Y. (1999). Thalamic inputs to striatal interneurons in monkeys: synaptic organization and co-localization of calcium binding proteins. Neuroscience 89 , 1189-1208.

Singer, H. S., Szymanski, S., Giuliano, J., Yokoi, F., Dogan, A. S., Brasic, J. R., Zhou, Y., Grace, A. A., and Wong, D. F. (2002). Elevated intrasynaptic 
dopamine release in Tourette's syndrome measured by PET. Am. J. Psychiatry 159, 1329-1336.

Smith, A. D., and Bolam, J. P. (1990). The neural network of the basal ganglia as revealed by the study of synaptic connections of identified neurones. Trends Neurosci. 13, 259-265.

Smith, R., Chung, H., Rundquist, S., Maat-Schieman, M. L., Colgan, L., Englund, E., Liu, Y. J., Roos, R. A., Faull, R. L., Brundin, P., and Li, J. Y. (2006). Cholinergic neuronal defect without cell loss in Huntington's disease. Hum. Mol. Genet. 15, 3119-3131.

Smith, Y., and Villalba, R. (2008). Striatal and extrastriatal dopamine in the basal ganglia: an overview of its anatomical organization in normal and Parkinsonian brains. Mov. Disord. 23(Suppl. 3), S534-S547.

Spokes, E. G. (1980). Neurochemical alterations in Huntington's chorea: a study of post-mortem brain tissue. Brain 103, 179-210.

Sullivan, M. A., Chen, H., and Morikawa, H. (2008). Recurrent inhibitory network among striatal cholinergic interneurons. J. Neurosci. 28, 8682-8690.

Surmeier, D. J., Plotkin, J., and Shen, W. (2009). Dopamine and synaptic plasticity in dorsal striatal circuits controlling action selection. Curr. Opin. Neurobiol. 19, 621-628.

Suzuki, M., Desmond, T. J., Albin, R. L., and Frey, K. A. (2001a). Vesicular neurotransmitter transporters in Huntington's disease: initial observations and comparison with traditional synaptic markers. Synapse 41, 329-336.

Suzuki, T., Miura, M., Nishimura, K., and Aosaki, T. (2001b).
Dopamine-dependent synaptic plasticity in the striatal cholinergic interneurons. J. Neurosci. 21, 6492-6501.

Suzuki, M., Desmond, T. J., Albin, R. L., and Frey, K. A. (2002). Cholinergic vesicular transporters in progressive supranuclear palsy. Neurology 58, 1013-1018.

Tepper, J. M., and Bolam, J. P. (2004). Functional diversity and specificity of neostriatal interneurons. Curr. Opin. Neurobiol. 14, 685-692.

Tepper, J. M., Tecuapetla, F., Koós, T., and Ibáñez-Sandoval, O. (2010). Heterogeneity and diversity of striatal GABAergic interneurons. Front. Neuroanat. 4:150. doi: 10.3389/ fnana.2010.00150

Thomas, T. M., Smith, Y., Levey, A. I., and Hersch, S. M. (2000). Cortical inputs to $\mathrm{m} 2$-immunoreactive striatal interneurons in rat and monkey. Synapse 37, 252-261.

Threlfell, S., Clements, M. A., Khodai, T., Pienaar, I. S., Exley, R., Wess, J., and Cragg, S. J. (2010). Striatal muscarinic receptors promote activity dependence of dopamine transmission via distinct receptor subtypes on cholinergic interneurons in ventral versus dorsal striatum. J. Neurosci. 30, 3398-3408.

van Vulpen, E. H., and van der Kooy, D. (1998). Striatal cholinergic interneurons: birthdates predict compartmental localization. Brain Res. Dev. Brain Res. 109, 51-58.

Vetter, J. M., Jehle, T., Heinemeyer, J., Franz, P., Behrens, P. F., Jackisch, R., Landwehrmeyer, G. B., and Feuerstein, T. J. (2003). Mice transgenic for exon 1 of Huntington's disease: properties of cholinergic and dopaminergic pre-synaptic function in the striatum. J. Neurochem. 85, 1054-1063.

Wada, E., Wada, K., Boulter, J., Deneris, E., Heinemann, S., Patrick, J., and Swanson, L. W. (1989). Distribution of alpha 2 , alpha 3 , alpha 4 , and beta 2 neuronal nicotinic receptor subunit mRNAs in the central nervous system: a hybridization histochemical study in the rat. J. Comp. Neurol. 284, 314-335.

Wang, Z., Kai, L., Day, M., Ronesi, J., Yin, H. H., Ding, J., Tkatch, T., Lovinger, D. M., and Surmeier, D. J. (2006). Dopaminergic control of corticostriatal long-term synaptic depression in medium spiny neurons is mediated by cholinergic interneurons. Neuron 50, 443-452.

Warren, N. M., Piggott, M. A., Perry, E. K., and Burn, D. J. (2005). Cholinergic systems in progressive supranuclear palsy. Brain 128, 239-249.

Wilson, C. J. (2005). The mechanism of intrinsic amplification of hyperpolarizations and spontaneous bursting in striatal cholinergic interneurons. Neuron 45, 575-585.

Wilson, C. J., Chang, H. T., and Kitai, S. T. (1990). Firing patterns and synaptic potentials of identified giant aspiny interneurons in the rat neostriatum. J. Neurosci. 10, 508-519.

Wilson, C. J., and Goldberg, J. A. (2006) Origin of the slow afterhyperpolarization and slow rhythmic bursting in striatal cholinergic interneurons. J. Neurophysiol. 95, 196-204.

Yan, Z., Flores-Hernandez, J., and Surmeier, D. J. (2001). Coordinated expression of muscarinic receptor messenger RNAs in striatal medium spiny neurons. Neuroscience 103, 1017-1024.

Yan, Z., and Surmeier, D. J. (1996). Muscarinic $(\mathrm{m} 2 / \mathrm{m} 4)$ receptors reduce
$\mathrm{N}$ - and P-type Ca2+ currents in rat neostriatal cholinergic interneurons through a fast, membrane-delimited, G-protein pathway. J. Neurosci. 16, 2592-2604.

Yan, Z., and Surmeier, D. J. (1997). D5 dopamine receptors enhance $\mathrm{Zn} 2+$ -sensitive GABA(A) currents in striatal cholinergic interneurons through a PKA/PP1 cascade. Neuron 19, 1115-1126.

Yin, H. H., and Knowlton, B. J. (2006). The role of the basal ganglia in habit formation. Nat. Rev. Neurosci. 7, 464-476.

Zhou, F. M., Wilson, C. J., and Dani, J. A. (2002). Cholinergic interneuron characteristics and nicotinic properties in the striatum. J. Neurobiol. 53, 590-605.

Conflict of Interest Statement: The authors declare that the research was conducted in the absence of any commercial or financial relationships that could be construed as a potential conflict of interest.

Received: 17 December 2010; accepted: 21 January 2011; published online: 07 February 2011.

Citation: Bonsi P, Cuomo D, Martella G, Madeo G, Schirinzi T, Puglisi F, Ponterio $G$ and Pisani A (2011) Centrality of striatal cholinergic transmission in basal ganglia function. Front. Neuroanat. 5:6. doi: 10.3389/fnana.2011.00006

Copyright (c) 2011 Bonsi, Cuomo, Martella, Madeo, Schirinzi, Puglisi, Ponterio and Pisani. This is an open-access article subject to an exclusive license agreement between the authors and Frontiers Media SA, which permits unrestricted use, distribution, and reproduction in any medium, provided the original authors and source are credited. 